\title{
Implementation of 3D Printing in Medical Care for Preoperative Planning of Complex Ventricular Septal Defect
}

\author{
Mina S Mousa ${ }^{1,2 *}$, Jonathan Ford ${ }^{1}$, Fadi Matar ${ }^{3}$, Todd R Hazelton ${ }^{1}$, Summer Decker ${ }^{1}$ \\ 1. Department of Radiology, University of South Florida Morsani College of Medicine, Tampa, FL, USA \\ 2. Mallinckrodt Institute of Radiology, Washington University School of Medicine, St. Louis, MO, USA
}

3. Department of Cardiovascular Sciences, University of South Florida Morsani College of Medicine, Tampa, FL, USA

\begin{abstract}
* Correspondence: Mina S. Mousa, M.D., Department of Radiology, University of South Florida Morsani College of Medicine, 2 Tampa General Circle, STC 6100, Tampa, FL 33606-3571, USA $\searrow$ minamousa@usf.edu)
\end{abstract}

Radiology Case. 2021 Nov; 15(11):17-29 :: DOI: 10.3941/jrcr.v15i11.4149

\begin{abstract}
Three-dimensional (3D) modeling and printing in medicine have emerged to encompass every aspect of medical applications. This ranges from education, illustration, and treatment, as well as patient care whether for purposes of diagnosis or treatment and surgical planning. In the past few decades, these novel tools have shown promising utility to help radiologists and the medical team to improve quality of patient care and outcomes via 3D printing application and utilization. This workflow will be illustrated through a ventricular septal defect (VSD) case at which 3D analysis was critical in the assessment and treatment planning of the patient's underlying medical condition.
\end{abstract}

\section{CASE REPORT}

\section{CASE REPORT}

An 82-year-old female with history of diabetes, coronary artery disease, and hypertension was referred to our institution for further assessment of multiple cardiac comorbidities. Her past medical history was significant for postoperative chest pain after a lumbar spine surgery for treatment of spinal stenosis. A 12-lead electrocardiogram (EKG) showed normal sinus rhythm and right bundle branch block, which could be related the patient's reported history of prior myocardial infarction (MI) (Figure 1). Transesophageal echocardiogram (TEE) at that time showed aortic valve dysfunction, left ventricular ejection fraction of 55-60\%, normal left ventricular wall motion, and ventricular septal defect (VSD) involving the inferior aspect of the interventricular muscular septum (Figure 2,3 ). The aortic valve dysfunction showed: moderate stenosis with mild to moderate regurgitation; peak velocity: $261 \mathrm{~cm} / \mathrm{s}$; and the ratio of left ventricular outflow tract (LVOT) peak velocity to aortic valve (AV) peak velocity, also known as LVOT/AV ratio: 0.26 -indicating moderate aortic stenosis. The VSD measured $1.1 \mathrm{~cm}$ in diameter with multiple suspected connections to right ventricular cavity, which showed left to right shunt flow with a peak velocity of 515 $\mathrm{cm} / \mathrm{s}$ and a peak gradient of $106 \mathrm{mmHg}$ (Figure 3). The VSD was located in the inferior aspect of the interventricular muscular septum $3.6 \mathrm{~cm}$ from the mitral valve annulus and 4.1 $\mathrm{cm}$ from the left ventricular apex (Figure 4). Upon further investigation, the patient reported 15-year chronic history of incidentally found heart murmur during routine outpatient visit that she never followed-up on, possibly related to the patient's VSD, which was presumed to be post-MI in etiology. The patient's comorbidities and recent spine surgery prevented 
immediate cardiac catheterization at the outside hospital facility.

The patient was stabilized medically and discharged home but continued to report progressively worsening mild dyspnea and low activity tolerance. The patient was therefore referred to our institution cardiology service for further workup. A gated cardiac computed tomography angiogram (CTA) was performed to assess for transcatheter aortic valve repair (TAVR) planning and accessibility of VSD for closure device. The CTA showed aortic valvular sclerosis, mitral annular calcifications, inferior interventricular muscular septum VSD, dilated pulmonary arteries and an enlarged left atrium (Figure 4). A diagnostic and therapeutic left heart catheterization (LHC) was then performed, which showed diffuse right coronary artery (RCA) atherosclerosis causing moderate stenosis near the origin, which was treated with three Xience drug eluting stents (DES) (figure 5). In addition, the patient received an aortic valve TAVR using a $26 \mathrm{~mm}$ Sapien aortic valve bioprosthesis (Figure 6). The patient's procedure was complicated by left femoral artery access occlusion necessitating vascular surgical repair using ipsilateral great saphenous vein (GSV) patch. The patient also suffered postTAVR complete atrioventricular block (Figure 7), which required placement of cardiac pacing device using ACCOLADETM pacemaker (Boston Scientific, model L301) via right femoral vein access (figure 8 ). These complications had led to prolonged hospitalization and further deferment of the VSD closure procedure.

Post-intervention EKG demonstrated post-procedural changes of cardiac pacer device placement, which showed expected electronic atrial pacemaker signal on the EKG tracer, normal sinus rhythm, along with resolution of the previously seen right bundle branch block (Figure 9).

In addition, postprocedural echocardiogram showed proper positioning of TAVR without valvular dysfunction, and normal biometrics of the aortic valve prothesis (figure 10). The echocardiogram showed no signs of valvular stenosis or regurgitation; transvalvular peak velocity: $102 \mathrm{~cm} / \mathrm{s}$; mean velocity: $67.5 \mathrm{~cm} / \mathrm{s}$; and postoperative LVOT/AV ratio: 0.76 (previously measured 0.25 on preoperative echocardiogram), which indicates resolution of the aortic stenosis (Figure 10).

During this current admission and prior to the patient's discharge, the patient's case was discussed at interventional cardiology conference and the radiology department was consulted for further characterization of the patient's VSD given the presumed complexity on CTA images. Our department's 3D Clinical Applications Division and Advanced Imaging Lab was able to provide a 3D print of the patient's VSD by using the CTA dataset. The 3D print revealed that the patient's VSD had complex anatomy with three fenestrations involving the right aspect of the VSD and was not simply a single defect (Figures 11, 12). Treatment of such VSD would require one large or multiple amplatzer devices potentially leading to multiple complications; such as, prolonged procedure time, amplatzer device detachment, formation of blood clots, which can lead to embolic strokes, or bacterial colonization within the small fenestrations, which increases the risk for infectious endocarditis and subsequently postoperative septic emboli. Our multidisciplinary team concluded that having an anatomically complex VSD with multiple fenestrations would pose more long-term postoperative complications to the patient than if left untreated, and that the postoperative risks in these situations would outweigh the benefits of attempting VSD closure. Due to the complex anatomy of the VSD and the patient's multiple co-morbidities, the patient was therefore deemed a poor candidate for VSD closure and further treatment was deferred.

The patient was discharged home and a six-month outpatient clinic visit follow-up showed overall improvement in the patient's symptoms, increase exercise tolerability, and reduction in the frequency of reported dyspnea or chest pain. This case highlights the critical role 3D printing can play in management of complex patients and in providing value added care especially in perioperative planning.

\section{MATERIAL AND METHODS:}

Imaging acquisition was performed via Toshiba Aquilion Prime, $0.5 \mathrm{~mm}$ slice thickness, with $219.65 \mathrm{~mm}$ field of view (FOV) using a gated cardiac CTA. We used 3D software assembly: Mimics Innovation Suite Medical 20.0 and 3-matic 12.0, by Materialise (C-FDA cleared medical application. Implementation was done using Form2-SLA Printer, offered by Formlabs, which employs liquid resin, which allows printing flexible or rigid material. Post-processing of flexible print was performed using isopropyl alcohol wash and then was cured using ultraviolet light bath.

\section{DISCUSSION}

\section{Etiology \& Demographics:}

VSD is the most common congenital heart disease in children, and is considered the second most common form of adult congenital heart disease following bicuspid aortic valve $(1,2)$. The congenital form of VSD can happen in isolation in about $0.3 \%$ of all newborns, or as a part of complex congenital heart disease (CHD), which accounts for $37 \%$ of all CHD (1, 3 ). The etiology of congenital VSD is failure of formation and closure of the interventricular (IV) septum during embryologic development. The acquired form of VSD in adulthood occurs due to various etiologies and is commonly encountered secondary to myocardial infarction, infectious endocarditis, or iatrogenic injury (4-6)

\section{Clinical \& Imaging Findings:}

Color Doppler ultrasound transthoracic echocardiography (TTE) is considered the gold standard of VSD diagnosis and evaluation with $95 \%$ sensitivity. TTE is also important in evaluating the size, shape, number, and location of VSD and providing hemodynamic information of the direction of the jet size and shunt direction $(7,8)$.

In addition to ultrasound (US), computed tomography (CT) and magnetic resonance imaging (MRI) cardiac imaging are considered superior imaging modalities that can provide valuable information regarding the anatomy and morphology 
of the VSD. In particular, cardiac CT higher resolution capabilities can further delineate any complex anatomy of the VSD shape and morphology, and cardiac MRI can help in evaluating the jet size and direction, along with underlying cardiac pathology such as MI, infectious endocarditis, or various types of congenital or restrictive heart diseases $(9,10)$.

Three-dimensional (3D) modeling and printing have been utilized in the recent years as advanced imaging tools in medical care and diagnostic workup of unusual cases with complex anatomy and pathology. This emerging technology is revolutionizing patient-centered care by providing virtual and physical representation of the patient's own complex anatomy and pathology in 3D (11-13). Through this technology, radiologists can provide additional diagnostic information that can improve patient quality and clinical outcomes (14-16).

New technologies like 3D modeling and printing also provide radiologists with novel tools to use in their practice to improve quality of patient care and outcomes $(11-13,17)$. Due to unfamiliarity with the technology to the majority of practicing radiologists, it may appear that it is not a tangible option for their practice. However, radiology has the opportunity to drive advancement of this technology to meet their unique needs, make it more feasible for every day clinical use, and add value to clinical practices $(14,15,18$, 19). In addition, 3D modeling and printing are promising tools that have the potential to revolutionize surgical planning and intervention in order to improve patient care and outcomes (14, 16, 17, 20, 21). This emerging technology can also potentially impact the future of medical training for surgical residents by providing a $3 \mathrm{D}$ printed model for preoperative planning (21-24).

\section{Treatment \& Prognosis:}

About $90 \%$ of isolated VSD cases are asymptomatic incidentally diagnosed during routine physical examination prior to spontaneous closure during childhood (1). Persistent VSD in adulthood can be treated with prophylactic endocarditis medications or surgical closure (25-27). Untreated cases are associated with minimal increased risk for congestive heart failure, arrhythmia, or endocarditis, compared to the general population (28). Various literature resources recommended surgical or endovascular intervention if a patient with VSD presents with symptoms, along with other factors such as, the location, size, and direction of the VSD shunt flow. A commonly used convention for classifying VSD based on size is comparing the VSD diameter to the aortic annulus diameter (AAD). For example, a small VSD measures less or equal to $25 \%$ of the AAD and is considered large when it is greater than $75 \%$ of the AAD. For patients with untreated chronic large left-to-right VSD shunt, the patient may develop pulmonary arterial hypertension secondary to irreversible vascular endothelial hypertrophy (25-28). Eisenmenger syndrome, which accounts for $10 \%$ to $15 \%$ of patients with untreated VSD, develops when the pulmonary pressure exceeds the systemic pressure leading right-to-left VSD shunt, which leads to admixture of unoxygenated blood into the systemic circulation. If the shunt volume is large enough, the patient may develop cyanotic heart disease (28).

\section{Differential Diagnoses:}

Differential diagnosis of cardiac wall defects includes: pseudoaneurysm, aneurysm, or diverticulum (29). Cardiac pseudoaneurysms are almost exclusively encountered in the left ventricular (LV) free wall secondary to prior infection, trauma, or ischemia. Pseudoaneurysms represent LV rupture contained by overlying adherent pericardium, which prevents frank tamponade (30). Approximately $10 \%$ of LV pseudoaneurysms are asymptomatic with symptomatic patients reporting occasional chest pain, palpitations, dyspnea, or syncope. This entity can be incidentally detected on echocardiogram, CT, or MRI as abrupt discontinuity of cardiac wall with orifice-to false aneurysm diameter ratio of more than 0.5 with internal turbulent blood flow, lack of aneurysmal wall calcification, and presence of a thrombus on MRI and US $(31,32)$.

Conversely, true cardiac aneurysms are thin myocardial wall outpouchings composed of fibrous tissue and necrotic cardiomyocytes, commonly encountered in the LV anterior wall, occasionally with septal involvement. Various etiologies have been linked to true aneurysms, including ischemia, infection, or trauma, with associated symptoms of chest pain, fatigue and palpitations (33). True aneurysms can be complicated by intramural thrombus formation leading to stroke or limb ischemia in the setting of thromboembolic disease. While left ventriculography conventional angiography is the gold standard, MRI, CT, and US can offer further details regarding the presence of wall calcification, transmural thrombus, wall dyskinesia, or ejection fraction abnormality (32). On US and CT, cardiac aneurysms would demonstrate thinning of normal myocardium replaced by thin fibrous tissue, which occasionally calcifies; while on MRI cardiac aneurysm usually presents as T2 hypointense thinning of the left ventricular wall with diffuse post-gadolinium delayed enhancement $(23,33)$.

Myocardial diverticulum is a congenital protrusion of the cardiac wall characterized by the presence of normal cardiomyocytes that can affect the left ventricular free wall, right ventricular apex, or rarely the IV septum (34). The majority are asymptomatic, but surgical resection is recommended to avoid long term complications such as heart failure, infection, or thromboembolism (35). Imaging findings on US usually demonstrate subtle anechoic wall defect without focal bulging or surrounding myocardial wall abnormal echogenicity (34). On CT, a diverticulum presents as an incomplete, noncalcified defect in the ventricular wall that follows blood pool attenuation. Similarly, on MRI it usually shows normal $\mathrm{T} 1$ and $\mathrm{T} 2$ signal of the myocardial signal, preserved normal myocardial thickness and enhancement, with focal defect that follows blood pool signal on all MRI sequences (36).

\section{TEACHING POINT}

3D Printing is a useful medical tool for the visualization of complex cardiac anatomy such as ventricular septal defects, which can impact the patient's clinical diagnosis and perioperative planning. 


\section{REFERENCES}

1. Dakkak W, Oliver TI. Ventricular Septal Defect. StatPearls [Internet]. 2020.

2. Zhang J, Ko JM, Guileyardo JM, Roberts WC. A review of spontaneous closure of ventricular septal defect. Proc (Bayl Univ Med Cent). 2015;28(4):516-20. PMID: 26424961.

3. Mostefa-Kara M, Houyel L, Bonnet D. Anatomy of the ventricular septal defect in congenital heart defects: a random association? Orphanet J Rare Dis. 2018;13(1):118. PMID: 30021599.

4. Thomas CS, Jr., Alford WC, Jr., Burrus GR, Glassford DM, Jr., Stoney WS. Urgent operation for acquired ventricular septal defect. Ann Surg. 1982;195(6):706-11. PMID: 7082062 .

5. Kretzer A, Amhaz H, Nicoara A, Kendall M, Glower D, Jones MM. A Case of Gerbode Ventricular Septal Defect Endocarditis. CASE (Phila). 2018;2(5):207-9. PMID: 30370384.

6. Uslu N, Kayacioglu I, Ates M, Eren M. 'Acquired' left ventricular to right atrial shunt after mitral valve replacement: detection by transthoracic colour Doppler echocardiography. Can J Cardiol. 2007;23(9):735-6. PMID: 17622397.

7. Hadeed K, Hascoët S, Karsenty C, Ratsimandresy M, Dulac $\mathrm{Y}$, Chausseray G, et al. Usefulness of echocardiographicfluoroscopic fusion imaging in children with congenital heart disease. Arch Cardiovasc Dis. 2018;111(6-7):399-410. PMID: 29853351.

8. Maagaard M, Heiberg J, Eckerström F, Asschenfeldt B, Rex $\mathrm{CE}$, Ringgaard $\mathrm{S}$, et al. Biventricular morphology in adults born with a ventricular septal defect. Cardiol Young. 2018;28(12):1379-85. PMID: 30160649.

9. Kilner PJ. The role of cardiovascular magnetic resonance in adults with congenital heart disease. Prog Cardiovasc Dis. 2011;54(3):295-304. PMID: 22014496.

10. Nicolay S, Salgado RA, Shivalkar B, Van Herck PL, Vrints C, Parizel PM. CT imaging features of atrioventricular shunts: what the radiologist must know. Insights Imaging. 2016;7(1):119-29. PMID: 26638005.

11. Abdullah KA, Reed W. 3D printing in medical imaging and healthcare services. Journal of medical radiation sciences. 2018;65(3):237-9. PMID: 29971971.

12. Aimar A, Palermo A, Innocenti B. The Role of 3D Printing in Medical Applications: A State of the Art. Journal of healthcare engineering. 2019;2019:5340616. PMID: 31019667.

13. Ballard DH, Trace AP, Ali S, Hodgdon T, Zygmont ME, DeBenedectis CM, et al. Clinical Applications of 3D Printing: Primer for Radiologists. Academic radiology. 2018;25(1):5265. PMID: 29030285.
14. Heller M, Bauer HK, Goetze E, Gielisch M, Roth KE, Drees $\mathrm{P}$, et al. Applications of patient-specific 3D printing in medicine. International journal of computerized dentistry. 2016;19(4):323-39. PMID: 28008429.

15. Hodgdon T, Danrad R, Patel MJ, Smith SE, Richardson ML, Ballard DH, et al. Logistics of Three-dimensional Printing: Primer for Radiologists. Academic radiology. 2018;25(1):40-51. PMID: 29030283.

16. Paul GM, Rezaienia A, Wen P, Condoor S, Parkar N, King W, et al. Medical Applications for 3D Printing: Recent Developments. Missouri medicine. 2018;115(1):75-81. PMID: 30228688 .

17. Chepelev L, Wake N, Ryan J, Althobaity W, Gupta A, Arribas E, et al. Radiological Society of North America (RSNA) 3D printing Special Interest Group (SIG): guidelines for medical 3D printing and appropriateness for clinical scenarios. 3D printing in medicine. 2018;4(1):11. PMID: 30649688 .

18. Dodziuk H. Applications of 3D printing in healthcare. Kardiochirurgia i torakochirurgia polska = Polish journal of cardio-thoracic surgery. 2016;13(3):283-93. PMID: 27785150.

19. Jamróz W, Szafraniec J, Kurek M, Jachowicz R. 3D Printing in Pharmaceutical and Medical Applications - Recent Achievements and Challenges. Pharmaceutical research. 2018;35(9):176. PMID: 29998405.

20. Mardis NJ. Emerging Technology and Applications of 3D Printing in the Medical Field. Missouri medicine. 2018;115(4):368-73. PMID: 30228770.

21. Squelch A. 3D printing and medical imaging. Journal of medical radiation sciences. 2018;65(3):171-2. PMID: 30175453.

22. Sun Z. 3D printing in medicine: current applications and future directions. Quantitative imaging in medicine and surgery. 2018;8(11):1069-77. PMID: 30701160.

23. Sun Z. Insights into 3D printing in medical applications. Quantitative imaging in medicine and surgery. 2019;9(1):1-5. PMID: 30788241.

24. Ventola CL. Medical Applications for 3D Printing: Current and Projected Uses. P \& T : a peer-reviewed journal for formulary management. 2014;39(10):704-11. PMID: 25336867.

25. McNicholas K, de Leval M, Stark J, Taylor JF, Macartney FJ. Surgical treatment of ventricular septal defect in infancy. Primary repair versus banding of pulmonary artery and later repair. Br Heart J. 1979;41(2): 133-8. PMID: 426962.

26. Duong DH, Pham QD. Closure of subarterial ventricular septal defect with minimally invasive surgical technique: A case report. Int J Surg Case Rep. 2019;58:142-4. PMID: 31039512 . 
27. Schipper M, Slieker MG, Schoof PH, Breur JM. Surgical Repair of Ventricular Septal Defect; Contemporary Results and Risk Factors for a Complicated Course. Pediatr Cardiol. 2017;38(2):264-70. PMID: 27872996.

28. Viswanathan S, Kumar RK. Should we close small ventricular septal defects? Ann Pediatr Cardiol. 2017;10(1):14. PMID: 28163421.

29. Makkuni P, Kotler MN, Figueredo VM. Diverticular and aneurysmal structures of the left ventricle in adults: report of a case within the context of a literature review. Tex Heart Inst J. 2010;37(6):699-705. PMID: 21224951.

30. Moreno R, Gordillo E, Zamorano J, Almeria C, GarciaRubira JC, Fernandez-Ortiz A, et al. Long term outcome of patients with postinfarction left ventricular pseudoaneurysm. Heart. 2003;89(10):1144-6. PMID: 12975400.

31. Faiza Z, Lee L. Left Ventricular False Aneurysm. In: StatPearls [Internet]. 2020.

32. Menke J, Sahlmann CO. Multimodal cardiac imaging of a postinfarction subvalvular left ventricular aneurysm. BMJ Case Rep. 2015;2015. PMID: 25716156.

33. Sattar Y, Alraies MC. Ventricular Aneurysm. In: StatPearls [Internet]. 2020 Apr 7.

34. Barberato SH, Barberato MF. Left ventricular diverticulum of the interventricular septum. Arq Bras Cardiol. 2015;104(1):e10-1. PMID: 25714410.

35. Uysal F, Bostan OM, Toprak MH, Signak IS, Cil E. Isolated congenital cardiac diverticulum originating from the left ventricular apex: Report of a pediatric case. Ann Pediatr Cardiol. 2016;9(2):195-6. PMID: 27212863.

36. D'Aloia A, Rovetta R, Vizzardi E, Bonadei I, Sciatti E, Metra M. A case of isolated left ventricle diverticulum. Heart Lung Vessel. 2014;6(4):280-1. PMID: 25436210.

\section{FIGURES}

Figure 1 (bottom): An 82-year-old female with history of multiple cardiac comorbidities presented with chest pain after lumbar spine surgery at an outside hospital. FINDINGS: 12lead electrocardiogram showing sinus rhythm and right bundle branch block, which could be related the patient's reported history of prior myocardial infarction. TECHNIQUE: 12 lead Electrocardiogram

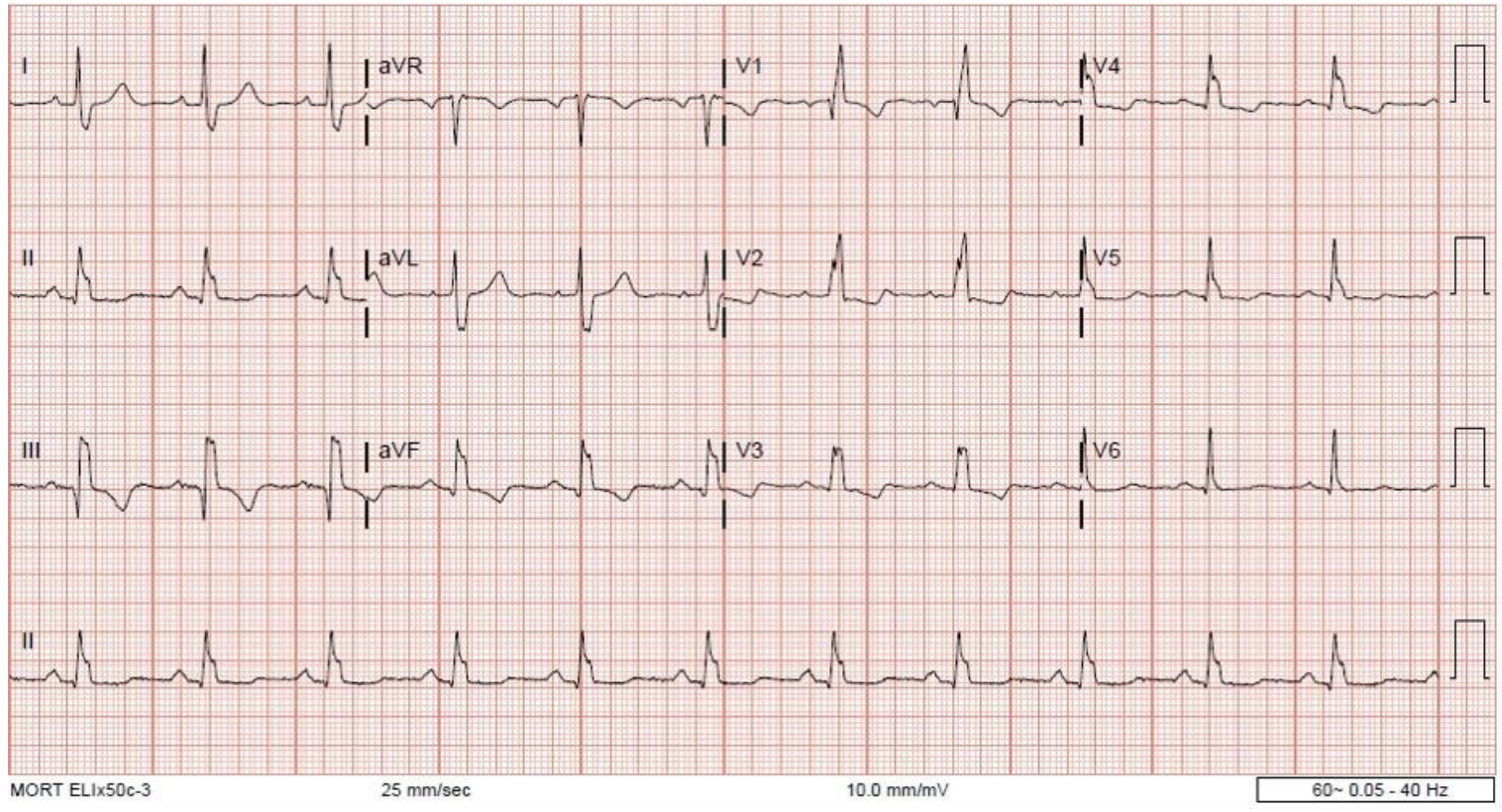




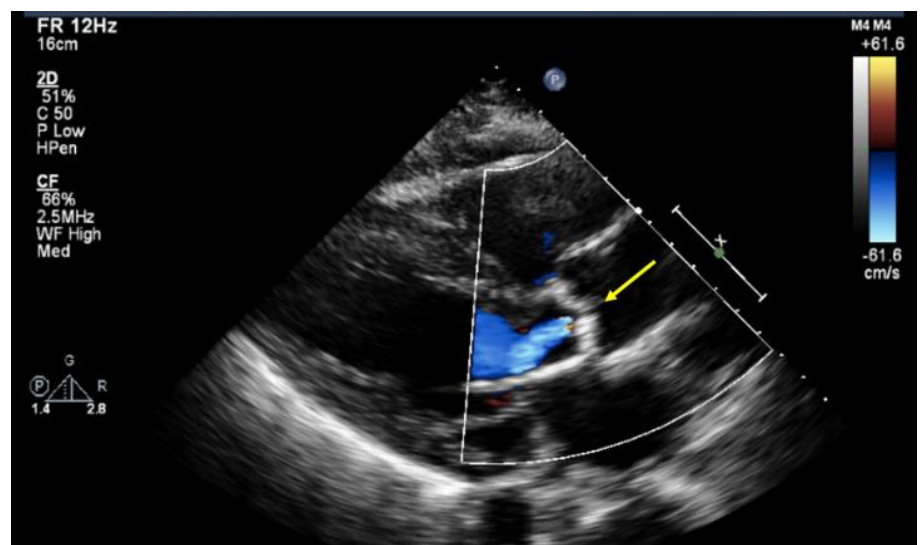

Figure 2 (left): An 82-year-old female with history of multiple cardiac comorbidities.

FINDINGS: 2D echocardiogram at the level of the aortic valve demonstrates thickening of the aortic valve leaflets indicating aortic stenosis. A blue jet of color flow in the proximal aorta suggesting a superimposed component of aortic regurgitation.

TECHNIQUE: 2D Doppler ultrasound echocardiogram at the level of the aortic valve, using $12 \mathrm{~Hz}$ frequency probe.

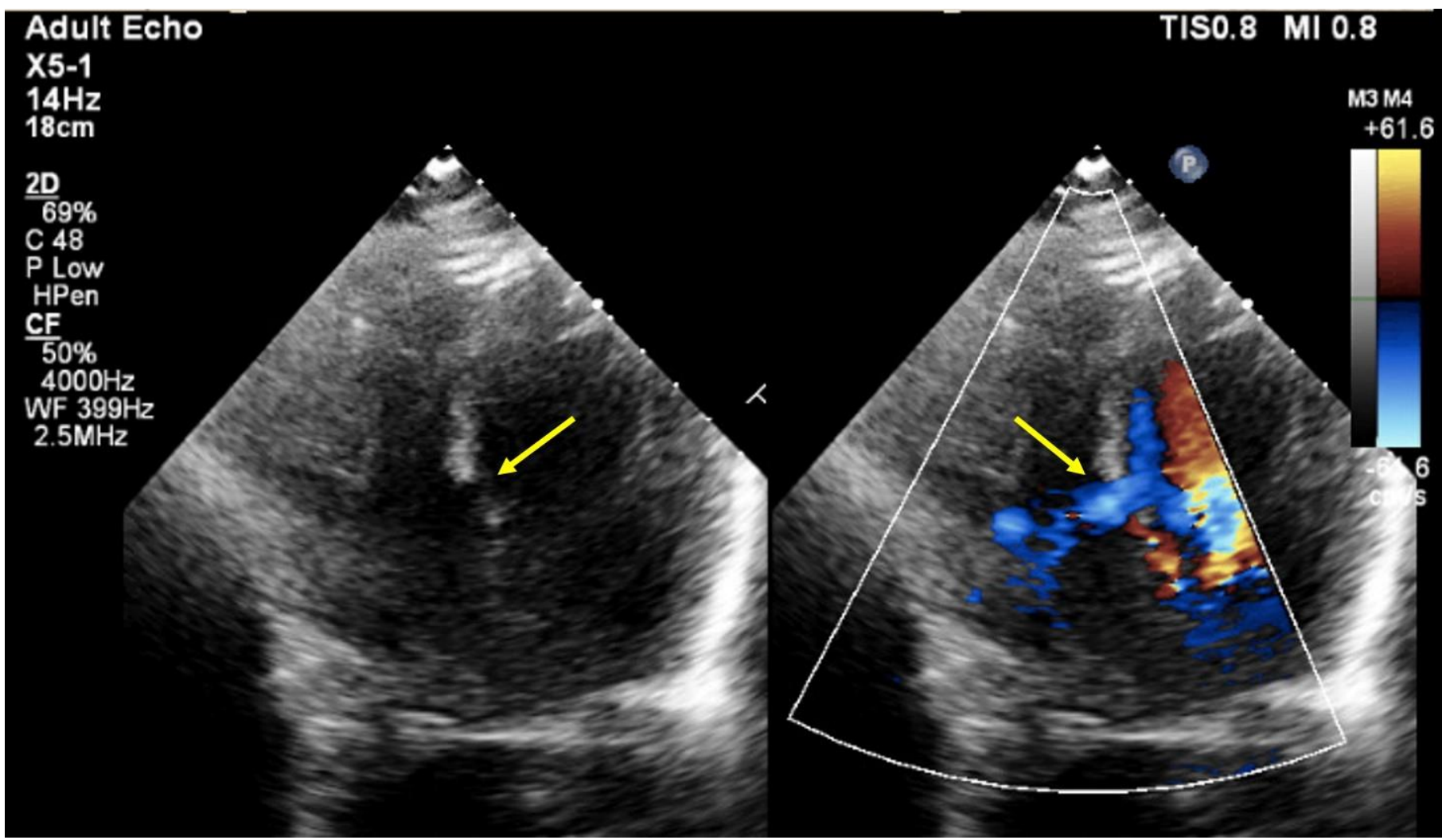

Figure 3: An 82-year-old female with history of multiple cardiac comorbidities.

FINDINGS: 2D echocardiogram ultrasound at the level of the interventricular septum demonstrates ventricular septal defect and left to right ventricular shunt, indicated by a blue color flow jet.

TECHNIQUE: 2D Doppler ultrasound echocardiogram at the level of the interventricular septum using $14 \mathrm{~Hz}$ frequency probe. 


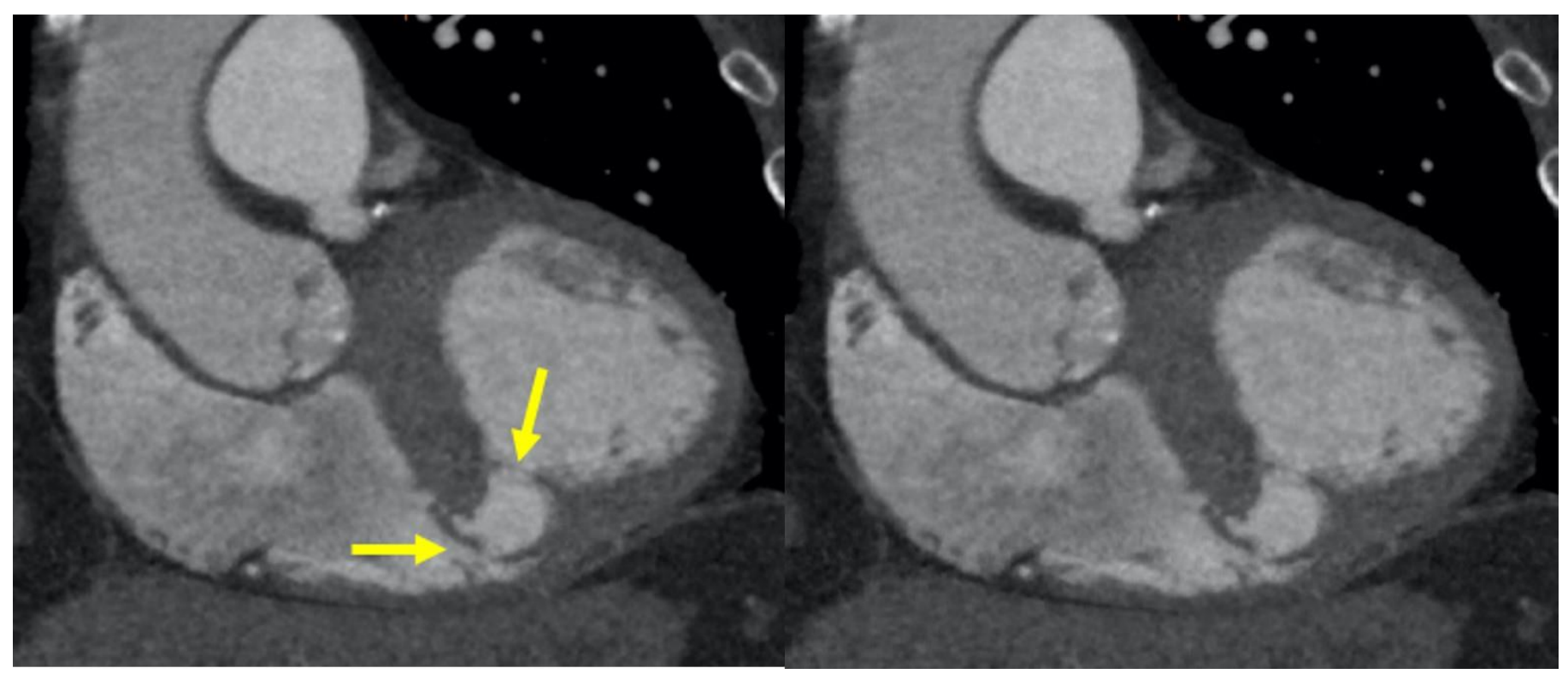

Figure 4: An 82-year-old female with history of multiple cardiac comorbidities.

FINDINGS: Arterial phase coronal contrast enhanced computed tomography image of the heart demonstrates a small interventricular defect involving the inferior muscular aspect of the interventricular septum with complex morphology measuring approximately $1.1 \mathrm{~cm}$ in diameter. This finding was presumed to be related to the patient's reported history of prior myocardial infarction.

TECHNIQUE: 2D reformatted coronal CT, $430 \mathrm{mAs}, 100 \mathrm{kV}, 1 \mathrm{~mm}$ slice thickness, $60 \mathrm{ml}$ of Isovue-370 contrast intravenous contrast.

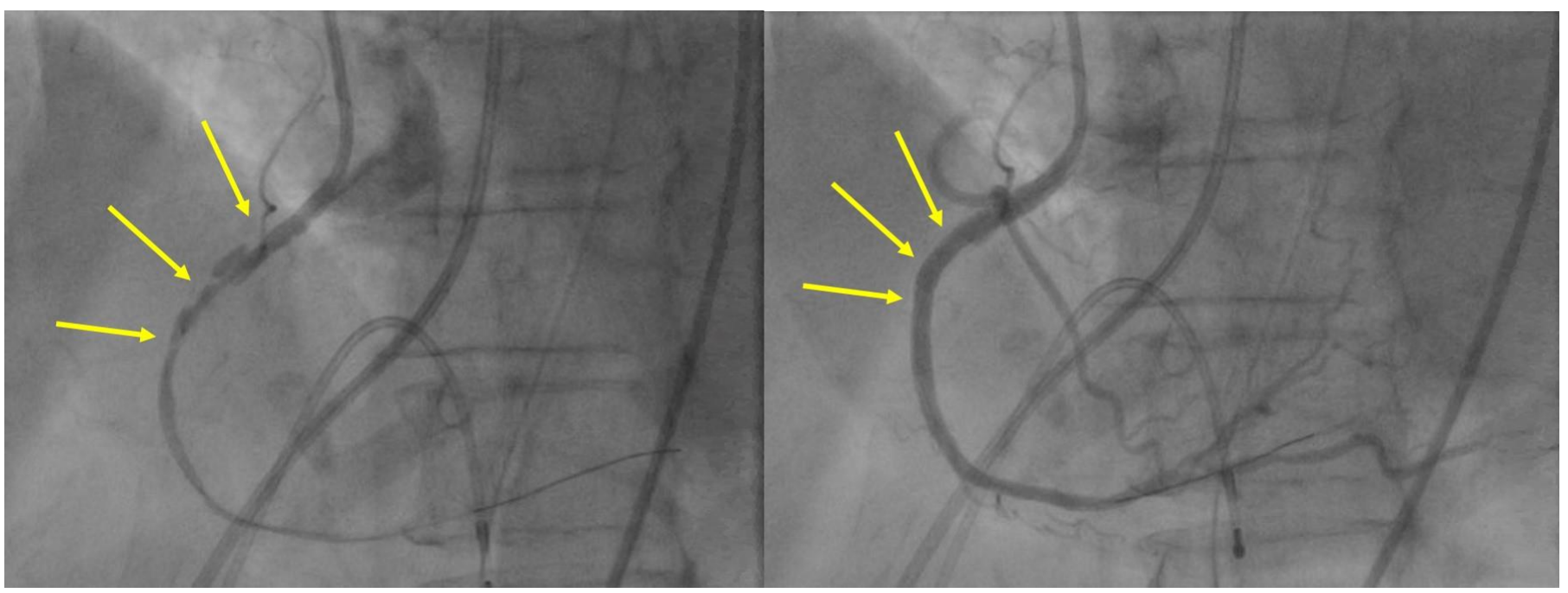

Figure 5: An 82-year-old female with history of multiple cardiac comorbidities status post left heart catheterization fluoroscopic procedure.

FINDINGS: Left femoral artery catheterization fluoroscopic exam demonstrates multifocal areas of high grade right coronary artery stenosis (yellow arrows) near the origin (Figure 5a). Post-stenting image shows improvement in the sites of focal right coronary artery stenosis (Figure 5b).

TECHNIQUE: Fluoroscopic images of the chest at the level of the right coronary artery after the administration of Isovue-370 intravenous iodinated contrast. 


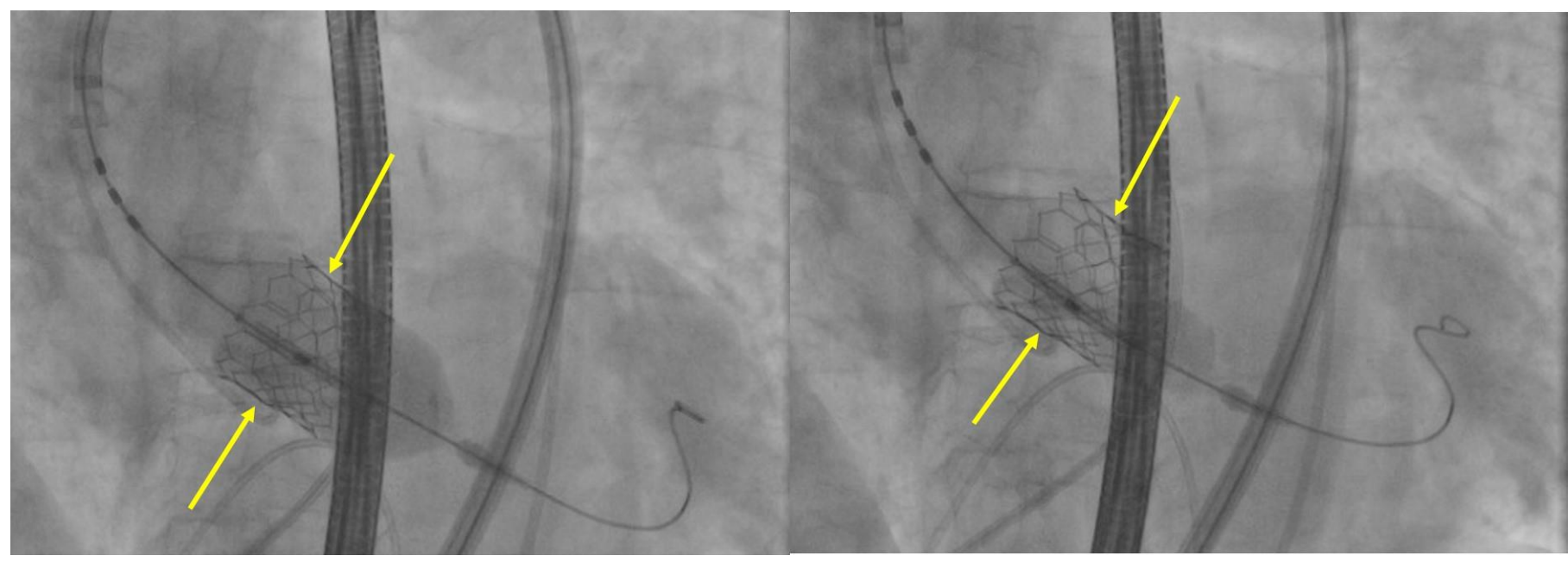

Figure 6: An 82-year-old female with history of multiple cardiac comorbidities status post left heart catheterization fluoroscopic procedure.

FINDINGS: Left femoral artery catheterization fluoroscopic exam demonstrates successful placement of percutaneous transcatheter aortic valve repair using a $26 \mathrm{~mm}$ Sapien aortic valve bioprosthesis (Figures 6a-b).

TECHNIQUE: Fluoroscopic images of the chest at the level of the aortic valve after the administration of Isovue-370 intravenous iodinated contrast.

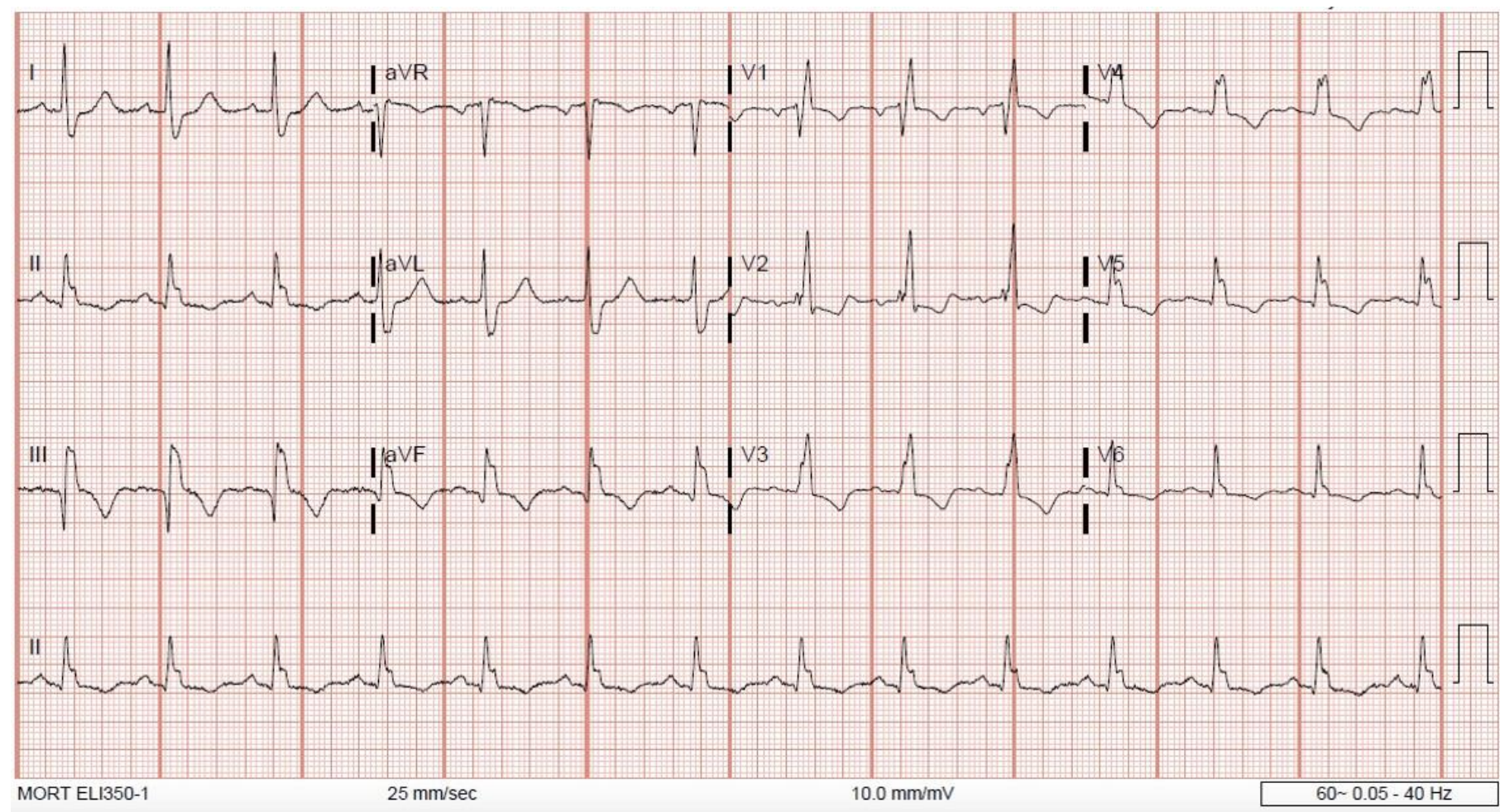

Figure 7: An 82-year-old female with history of multiple cardiac comorbidities status post right coronary artery stenting and percutaneous aortic valve repair procedure.

FINDINGS: 12-lead electrocardiogram demonstrates new complete atrioventricular block likely post-procedural in etiology.

TECHNIQUE: 12 lead Electrocardiogram. 


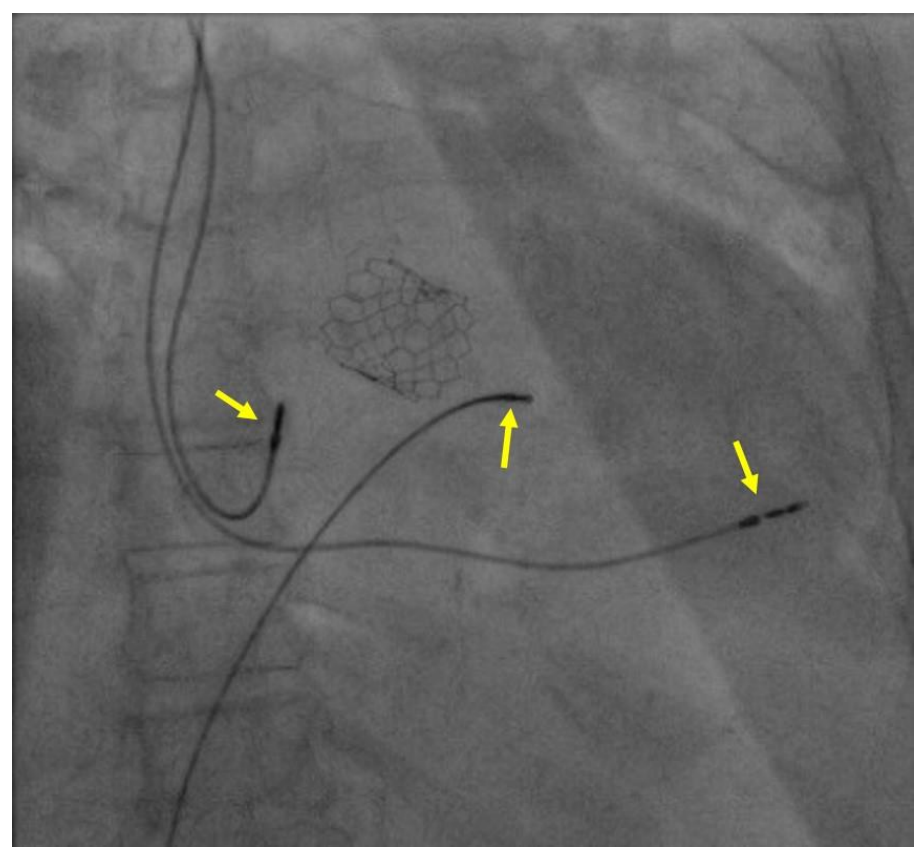

Figure 8 (left): An 82-year-old female with history of multiple cardiac comorbidities status post right coronary artery stenting and percutaneous aortic valve repair procedure. FINDINGS: right femoral venous catheterization fluoroscopic exam demonstrates successful placement of cardiac pacing triple-lead device using ACCOLADETM pacemaker (Boston Scientific, model L301).

TECHNIQUE: Fluoroscopic images of the chest at the level of the cardiac silhouette.

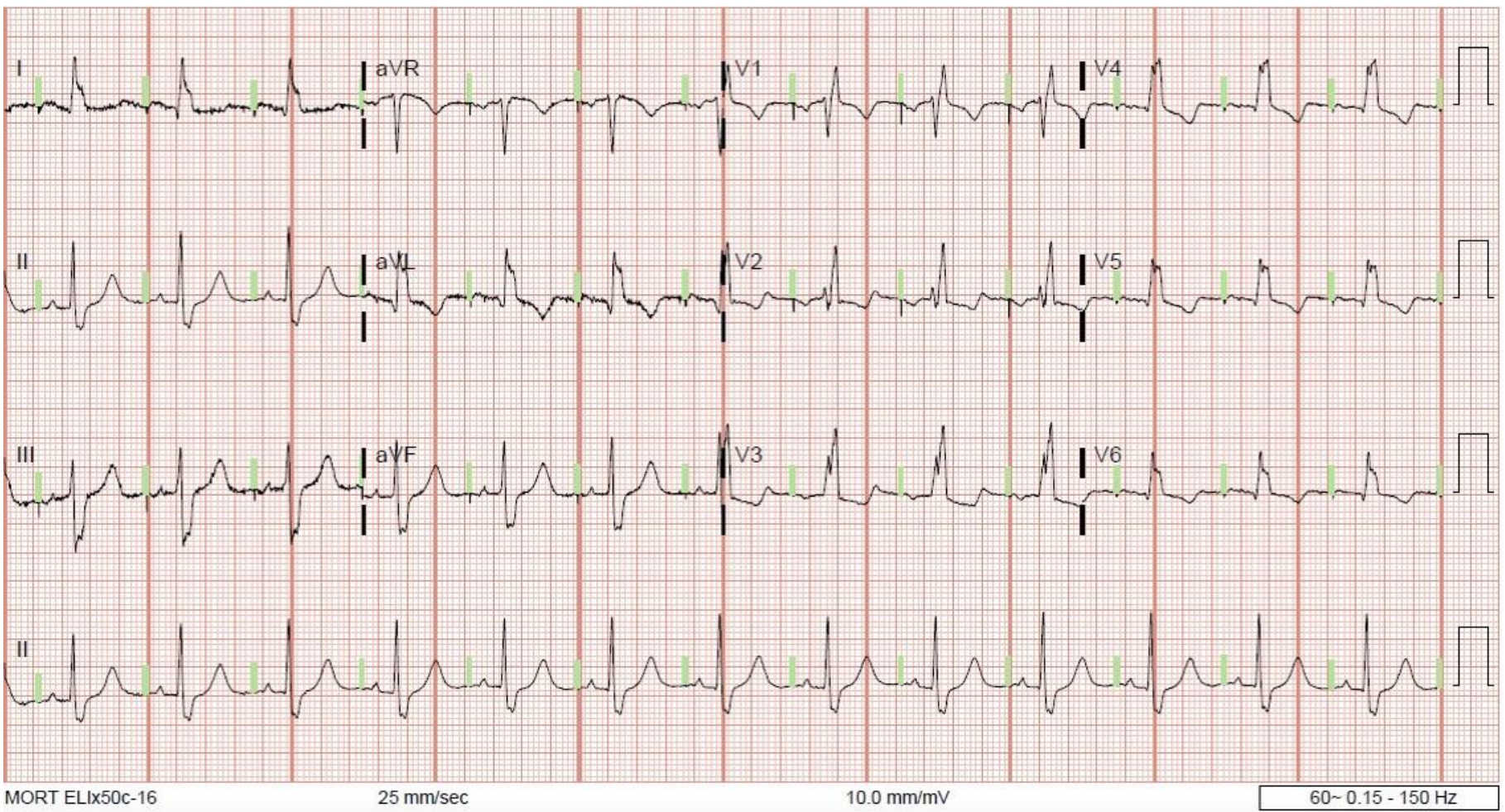

Figure 9: An 82-year-old female with history of multiple cardiac comorbidities status post cardiac pacing device placement.

FINDINGS: 12-lead electrocardiogram demonstrates electronic atrial pacemaker tracer, intraventricular conduction delay, and resolution of the previously seen right bundle branch block.

TECHNIQUE: 12 lead Electrocardiogram. 


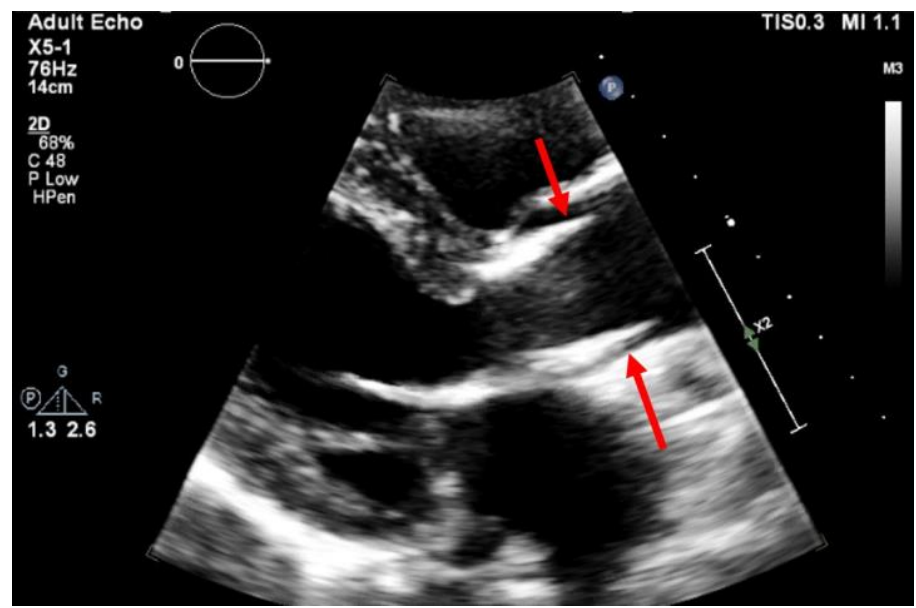

Figure 10 (left): An 82-year-old female with history of multiple cardiac comorbidities status post percutaneous aortic valve repair.

FINDINGS: 2D echocardiogram at the level of the aortic valve demonstrates successful placement of transcatheter aortic valve repair using a $26 \mathrm{~mm}$ Sapien aortic valve bioprosthesis. Transvalvular peak velocity: $102 \mathrm{~cm} / \mathrm{s}$ and mean velocity: $67.5 \mathrm{~cm} / \mathrm{s}$; left ventricular outflow tract to aortic valve ratio: 0.76 , which indicates resolution of the aortic stenosis.

TECHNIQUE: 2D echocardiogram at the level of the aortic valve using high frequency ultrasound probe to assess for percutaneous aortic valve prothesis placement.
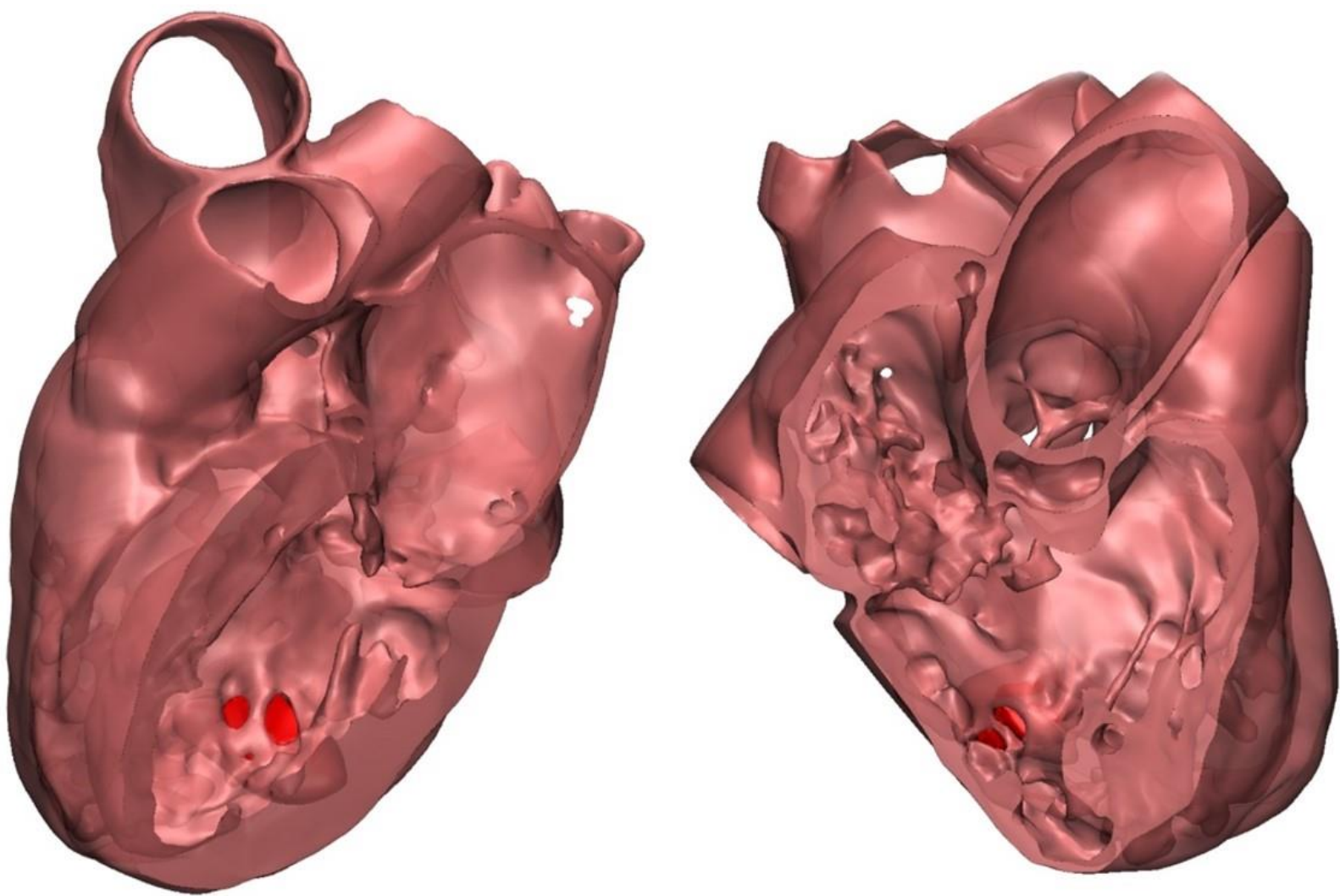

Figure 11: An 82-year-old female with history of multiple cardiac comorbidities.

A 3D heart model designed using software assembly: Mimics Innovation Suite Medical 20.0 and 3-matic 12.0, by Materialise (CFDA cleared medical application, which shows complex anatomy with three ventricular septal defect fenestrations (red labels). 


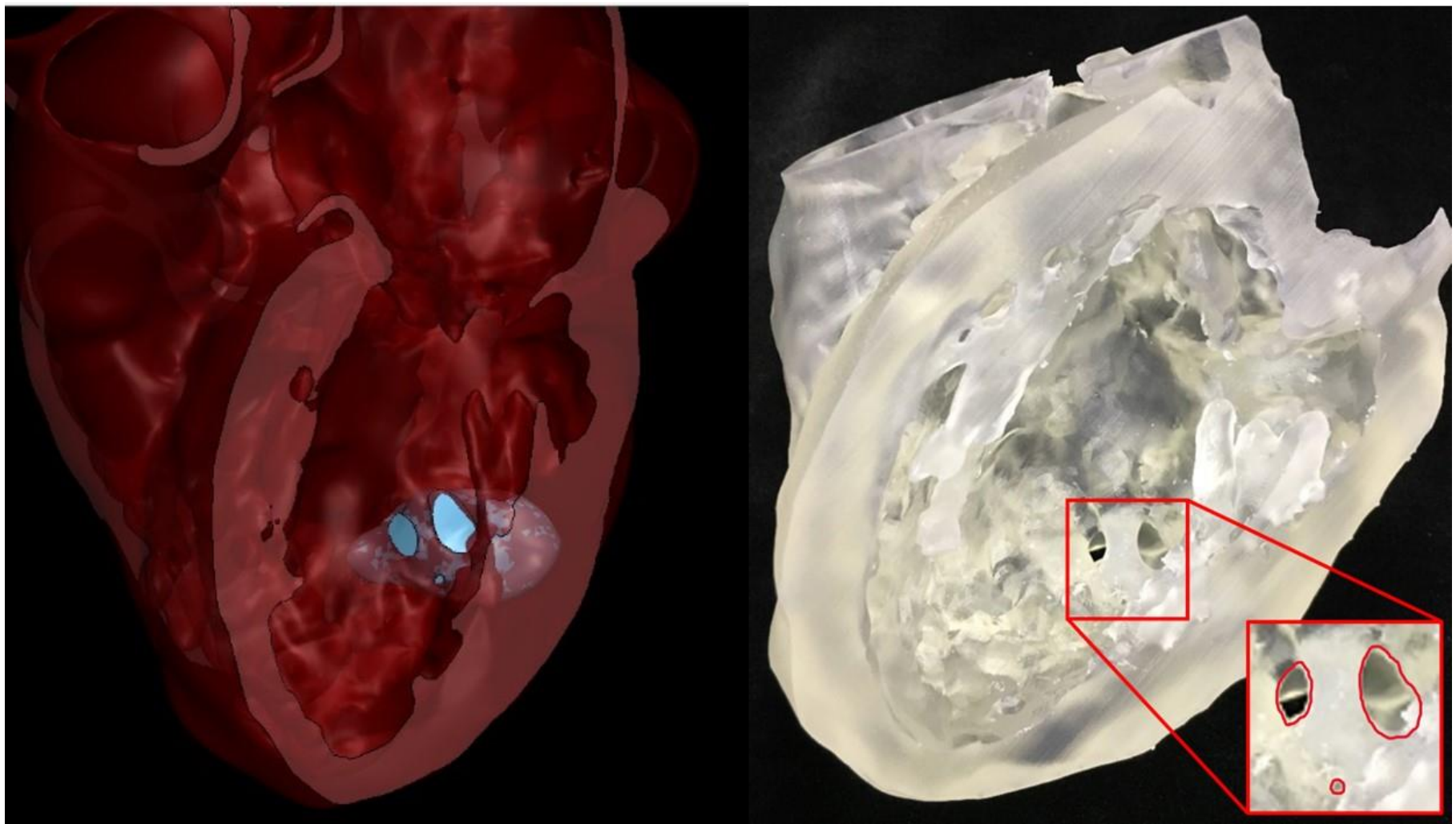

Figure 12: An 82-year-old female with history of multiple cardiac comorbidities.

Figure 12a: 3D heart model created using software assembly: Mimics Innovation Suite Medical 20.0 and 3-matic 12.0, by Materialise(C-FDA cleared medical application, which shows complex anatomy with three ventricular septal defect fenestrations.

Figure 12b: 3D final silicon print of the heart defect created using Form2-SLA Printer, offered by Formlabs employing liquid resin. The ventricular septal defect as shown in the zoomed 3D print image (outlined by a red marker) shows a complex anatomy with three fenestrations, separated by thin membrane, not a single defect as presumed initially. The three fenestrations are of various sizes: $2 \mathrm{~mm}$ (the most inferior fenestration), $11 \mathrm{~mm}$ (the top left side of the image), and $15 \mathrm{~mm}$ (the top right side of the image).

\begin{tabular}{|l|l|}
\hline Etiology & $\begin{array}{l}\text { - The congenital form of ventricular septal defect occurs secondary to interruption of the interventricular } \\
\text { septum formation during embryologic development. } \\
\text { - The acquired form occurs due to various etiologies, commonly including ischemia (myocardial infarction) } \\
\text { or infection, such as endocarditis. }\end{array}$ \\
\hline Incidence & $\begin{array}{l}\text { - Ventricular septal defect is the second most common congenital cardiac anomaly in adults and is also } \\
\text { considered the most common congenital abnormality in children accounting for } 37 \% \text { of all congenital } \\
\text { heart diseases, with isolated incidence of about } 0.3 \% \text { in newborns. }\end{array}$ \\
\hline Symptoms & $\begin{array}{l}\text { - Depending on the size of the ventricular septal defect, and the association with other congenital heart } \\
\text { diseases, an isolated, small ventricular septal defect is usually asymptomatic and is found incidentally on } \\
\text { physical exam. }\end{array}$ \\
\hline Gender and Age & $\begin{array}{l}\text { - It is commonly a congenital heart disease with no gender predilection. } \\
\text { - The acquired form of ventricular septal defect is seen in older population in the setting of myocardial } \\
\text { infarction. }\end{array}$ \\
\hline Treatment & $\begin{array}{l}\text { Approximately, 90\% of small, isolated, congenital ventricular septal defect will close spontaneously } \\
\text { during first year of life. } \\
\text { - Patients with persistent adult ventricular septal defect can benefit from surgical closure. } \\
\text { - Persistent adult ventricular septal defect has several comorbidities, such as congestive heart failure, } \\
\text { arrhythmia, or endocarditis. }\end{array}$ \\
\hline Prognosis & $\begin{array}{l}\text { Cardiac CT or MRI of ventricular septal defect is a muscular defect in the interventricular septum with } \\
\text { shunt of blood across the defect. The shunt can be small or large and can be unidirectional or } \\
\text { bidirectional. The size and direction of the ventricular septal defect shunt usually correspond to the } \\
\text { presence of symptoms and is a good indicator for the assessment of surgical intervention. }\end{array}$ \\
\hline Findings on &
\end{tabular}

Table 1: Summary table of ventricular septal defect. 


\begin{tabular}{|c|c|c|c|c|}
\hline Diagnosis & Symptoms & CT Findings & MRI Findings & US Findings \\
\hline $\begin{array}{l}\text { Ventricular } \\
\text { septal defect }\end{array}$ & $\begin{array}{l}\text { Isolated small } \\
\text { ventricular septal } \\
\text { defect are usually } \\
\text { asymptomatic. }\end{array}$ & $\begin{array}{l}\text { Focal defect within the } \\
\text { normal cardiac } \\
\text { muscle, filled with } \\
\text { iodinated contrast. CT } \\
\text { is Excellent in } \\
\text { delineating the size, } \\
\text { location, shape, and } \\
\text { complexity of } \\
\text { ventricular septal } \\
\text { defect. }\end{array}$ & $\begin{array}{l}\text { Focal defect within the } \\
\text { normal cardiac muscle } \\
\text { which follows the signal } \\
\text { of blood pool. MRI } \\
\text { imaging can provide } \\
\text { valuable information } \\
\text { regarding size, location, } \\
\text { and direction of jet flow } \\
\text { on phase contrast } \\
\text { sequences. }\end{array}$ & $\begin{array}{l}\text { TTE is the most sensitive } \\
\text { tool in detecting up to } 95 \% \\
\text { of ventricular septal defect } \\
\text { by providing information } \\
\text { regarding the morphology, } \\
\text { location, and size, number } \\
\text { of defects, and direction } \\
\text { and size of the ventricular } \\
\text { septal defect jet flow. }\end{array}$ \\
\hline $\begin{array}{l}\text { Cardiac wall } \\
\text { aneurysm }\end{array}$ & $\begin{array}{l}\text { Small aneurysms are } \\
\text { asymptomatic. Larger } \\
\text { aneurysms can cause } \\
\text { chest pain, fatigue, and } \\
\text { palpitation and are } \\
\text { commonly associated } \\
\text { with history of prior } \\
\text { myocardial infarction. }\end{array}$ & $\begin{array}{l}\text { Fibrous outpouching } \\
\text { of the LV anteroapical } \\
\text { wall, and occasionally } \\
\text { involving the IV } \\
\text { septum with } \\
\text { calcification. }\end{array}$ & $\begin{array}{l}\text { Thinning of the } \\
\text { myocardium which is T2 } \\
\text { hypointense with } \\
\text { delayed enhancement. } \\
\text { Turbulent flow and } \\
\text { thrombus are sometimes } \\
\text { encountered on MRI. }\end{array}$ & $\begin{array}{l}\text { Thinning of the } \\
\text { myocardium with turbulent } \\
\text { flow. It is commonly seen } \\
\text { in the LV anteroapical } \\
\text { wall, and occasionally } \\
\text { involving the septum. Low } \\
\text { ejection fraction and LV } \\
\text { wall dyskinesia is } \\
\text { commonly seen when it is } \\
\text { associated with prior } \\
\text { myocardial infarction. }\end{array}$ \\
\hline $\begin{array}{l}\text { Cardiac wall } \\
\text { pseudoaneurysm }\end{array}$ & $\begin{array}{l}10 \% \text { are asymptomatic } \\
\text { but can cause chest } \\
\text { pain, palpitations, } \\
\text { dyspnea, and syncope. }\end{array}$ & $\begin{array}{l}\text { Abrupt loss of cardiac } \\
\text { wall thickness with } \\
\text { adherent pericardium } \\
\text { with no calcification, } \\
\text { containing non- } \\
\text { thrombosed blood. }\end{array}$ & $\begin{array}{l}\text { Abrupt loss of } \\
\text { endocardium and } \\
\text { myocardial wall with } \\
\text { outpouching commonly } \\
\text { seen in the LV free wall } \\
\text { and apex. }\end{array}$ & $\begin{array}{l}\text { Sudden loss of cardiac wall } \\
\text { thickness with turbulent } \\
\text { flow commonly seen in the } \\
\text { LV free wall. }\end{array}$ \\
\hline $\begin{array}{l}\text { Cardiac wall } \\
\text { diverticulum }\end{array}$ & $\begin{array}{l}\text { Commonly } \\
\text { asymptomatic }\end{array}$ & $\begin{array}{l}\text { Focal incomplete, } \\
\text { noncalcified defect in } \\
\text { the interventricular } \\
\text { septum that follows } \\
\text { blood pool attenuation. }\end{array}$ & $\begin{array}{l}\text { Normal T1 and T2 signal } \\
\text { of the myocardium. } \\
\text { Preserved myocardial } \\
\text { thickness and } \\
\text { enhancement with focal } \\
\text { defect that follows blood } \\
\text { pool signal. }\end{array}$ & $\begin{array}{l}\text { Subtle anechoic wall defect } \\
\text { without focal bulging or } \\
\text { surrounding myocardial } \\
\text { wall abnormal } \\
\text { echogenicity. }\end{array}$ \\
\hline
\end{tabular}

Table 2: Differential diagnosis table for ventricular septal defect.

\section{ABBREVIATIONS}

2D $=$ Two-Dimensional

3D $=$ Three-Dimensional

$\mathrm{AAD}=$ aortic annulus diameter

$\mathrm{AV}=$ aortic valve

$\mathrm{CHD}=$ congenital heart disease

$\mathrm{CT}=$ computed tomography

CTA = computed tomography angiogram

DES $=$ drug eluting stents

$\mathrm{EKG}=$ electrocardiogram

$\mathrm{FOV}=$ field of view

$\mathrm{GSV}=$ great saphenous vein
IV $=$ interventricular

LHC $=$ left heart catheterization

$\mathrm{LV}=$ left ventricular

LVOT = left ventricular outflow tract

LVOT/AV = left ventricular outflow tract to aortic valve ratio

$\mathrm{MI}=$ myocardial infarction

MRI = magnetic resonance imaging

$\mathrm{RCA}=$ right coronary artery

TAVR $=$ transcatheter aortic valve repair

TEE $=$ Transesophageal echocardiogram

TTE $=$ transthoracic echocardiography (TTE)

US = ultrasound

VSD $=$ ventricular septal defect 


\section{KEYWORDS}

Ventricular Septal Defect; 3D Modeling; 3D Printing; Presurgical planning; 3D Printing in Medicine; 3D Printing Applications in Cardiac Imaging

\section{ACKNOWLEDGEMENTS}

We would like to thank Dr. Jay Nelson and Dr. Midhir Patel for their contribution at the early stage of this manuscript.

\section{Online access}

This publication is online available at:

www.radiologycases.com/index.php/radiologycases/article/view/4294

\section{Peer discussion}

Discuss this manuscript in our protected discussion forum at: www.radiolopolis.com/forums/JRCR

\section{Interactivity}

This publication is available as an interactive article with scroll, window/level, magnify and more features.

Available online at www.RadiologyCases.com

Published by EduRad

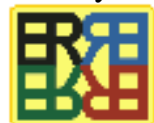

www.EduRad.org 